\title{
The Social Nature of Work Fragmentation: Revisiting Informal Workplace Communication
}

\author{
Aabhaas Arora ${ }^{1}$, Víctor M. González ${ }^{*}, 2$ and Stephen J. Payne ${ }^{3}$ \\ ${ }^{I}$ Manchester Business School, The University of Manchester, Booth Street East, M1, Manchester, UK \\ ${ }^{2}$ Department of Computer Science, Instituto Tecnológico Autónomo de México (ITAM), México \\ ${ }^{3}$ Department of Computer Science, University of Bath, UK
}

\begin{abstract}
Informal workplace communication is a central component of work and fundamental to understand its fragmentation. Previous studies point to external interruptions and multi-tasking preferences as the source of work fragmentation. Yet, although some empirical evidence exists on the role played by social informal interactions on interrupting work, we lack a more precise understanding of the degree of embeddedness they have within people's activities in the workplace. Based on the analysis of behavior of 28 information workers in the retail industry, this paper explores the nature of work fragmentation from the perspective of social informal interactions, aiming at shedding more light on the general phenomenon of multi-tasking in the workplace. Our results indicate that brevity and fragmentation of work is also common in the retail industry, and show that social (non-work related) informal interaction account for $9.7 \%$ of the activity observed, trigger about $21 \%$ of the external interruptions and are mostly initiated by colleagues.
\end{abstract}

Keywords: Social informal interactions, work fragmentation, switching, interruptions, non-related work, multi-tasking.

\section{INTRODUCTION}

Social informal interactions among people in the workplace are a common and often taken for granted part of the nature of most professional work activities. The effect of these interactions on people's productivity, however, is not clearly understood. Studies reporting on the experiences of tele-workers and people working from home often refer to them missing social interactions and finding ways to accommodate regular visits to the workplace in order to keep strong ties with co-workers [1]. Paradoxically, other studies highlight social interactions as a source of disruption and work fragmentation. For instance, Perlow reports on the practices of a software company and how excessive interruption took them to implement a negotiated time allocation strategy - quiet time during the morning when people were not supposed to interrupt each other - which was aimed to maximize sustained focus on solo work [2]. Beyond social bonding, whether or not social informal interactions have positive or negative consequences can also be understood from the perspective of work fragmentation and interruptions which has also been extensively reported in the literature (e.g. [3, 4]).

The main focus of this paper is to explore the way in which social informal workplace communication is actually embedded into people's activities and results in work fragmentation. Our view on informal workplace communication

*Address correspondence to this author at the Instituto Tecnológico Autónomo de México (ITAM), México; Tel: +52 555628 4000, Ext. 3614; Fax: +52 555628 4065;

E-mails: victor.gonzalez@itam.mx, victor.gonzalez@acm.org is based on that proposed by Kraut et al. [5] who discussed the value of this type of communicative behavior to enhance production functions (work related) and social functions (non-work related). They argue that through social informal non-work related communication, people sustain themselves as a group and support the needs of individual members [5]. Studies following up the direction proposed by Kraut et al. usually take an approach that does not necessarily differentiate between production and social functions of informal workplace communication, and instead emphasizes its interactive, synchronous, and spontaneous character. For instance the study conducted at Hewlett Packard (HP) labs in the early nineties $[2,6]$, although it focuses on enhancing our understanding about the nature and effects of informal communication, falls short of addressing how many of those exchanges are work-related or non-work related and how this affects work fragmentation.

More recently, often referring to the results reported by O'Conaill and Frohlich in their HP case [2], many studies have focused on the way people multitask and handle interruptions in the workplace [e.g. $[3,7,8]$. These studies have confirmed findings from managerial research $[9,10]$ and have extended our understanding about the fragmented nature of information work in general. However, most analyses tend to look at the sources of work fragmentation with regards the origin (external/internal) or the channels triggering the switching of activity, rather than work relatedness and the role of informal social interactions.

The significance of the work presented here lies in the fact that social informal aspects cannot be ignored while understanding workplace behavior, and, as has been shown 
by previous studies, they can be very relevant to understanding the use and adoption of information technologies [6]. For instance, the study of adoption of Instant Messaging in the workplace reveals that a significant proportion of communication exchanges with these tools is about non-work content and even humor [11]. Consequently, our study provides an additional understanding of how those social aspects influence the work fragmentation by differentiating the effects of work related and non-work related informal interactions. With those analytical lenses we explore different types of sources of interruption and activity switching as well as the type of person creating the interruption (interruptor). The study also contributes to enhance our understanding of information work in general by exploring a retail outlet in the suburbs of Mumbai (the financial capital of India). Within this hectic and communication intensive environment our results indicate that people observed spent about $48 \%$ of the time in informal communication, and echo similar results in terms of brevity and multitasking as reported in previous studies in other parts of the world.

\section{BACKGROUND}

Many previous workplace studies report that it has become quite common for information workers to experience a high level of discontinuity in the execution of their activities (e.g. [3, 4, 8]). This discontinuity is mainly because of an increase in the workload of the employees. As a result, people may have to leave one task pending in order to follow up on another. Apart from workload, there are a number of other factors, which add to the complexity of the activity of information workers such as electronic communication tools demanding constant switching (e.g, [12]). From the findings of those studies, it is clear that interaction with other people plays a role in work discontinuity. Workplace studies confirm that face-to-face interactions, e-mail messages, and phone calls are the main sources of interruptions. Interestingly, it would be very difficult to explain the level of collaboration and operational schemes of many modern workplaces without people being free to communicate with each other as spontaneously as required. Consequently, it seems that informal communication presents itself as a necessary 'evil' which is intrinsic to the nature of workplace activity.

The importance of informal communication has been highlighted by studies conducted by Kraut et al. indicating that it is beneficial for coordination to occur as it allows people to mingle with each other [5]. Kraut and his colleagues have argued that it is not possible to get familiar with co-workers if informal communication does not form a part of routine work practice [5]. Other studies strengthen and extend Kraut et al.'s arguments, by indicating that people's job satisfaction is dependent on frequent social interactions, and within scenarios tending to monotonous work, pauses and self initiated fragmentation for information interaction can serve to reduce boredom [11]. Thus, social informal communication may not just be the cause but also the motivation for initiating work fragmentation.

Most studies in multitasking and interruption in the workplace tend to ignore the presence of non-work related informal interactions when analyzing and reporting findings.
Results are often aggregated as part of generic categories of activity (e.g., 'Others', 'Personal') (e.g., [5]), or not included as part of the data set (e.g., [13]). In contrast, other studies, although not reporting detailed statistics on the amount of non-work related information interactions, still provide some evidence highlighting their relevance for information workers $[12,14]$. For example, Perlow reports on 35 days of informants' tracked activity that social interactions account for $10 \%$ [14]. Her analysis on the informants' perceptions with regards the helpfulness and urgency of those interactions, and the effects on interrupting activity, leaves out the social related ones, and focuses on those supporting coordination, support and work integration. More recent reports on informal communication in the workplace using chat-based tools highlight that non-work related content (including humor) accounts for $8 \%$ of the total messages exchanged by people [12]. We therefore consider it relevant to explore our data from the perspective of non-work related and work related informal interactions when analyzing work fragmentation.

\section{METHODOLOGY}

In order to fulfil the aim of attaining a detailed understanding of how information workers manage multiple activities in the retail industry, in the summer of 2008 we conducted an observational study at the head office of a retail outlet, Good Store, based in the suburbs of Mumbai in India. This retail outlet is the first of its kind to introduce catalogue shopping in India and is a joint venture with a major UK based retail chain. Around 150 employees work at this branch out of which 28 voluntarily took part in this research. All participants signed consent forms where we stated that all information collected would be kept anonymous and would be shared with their employers only as an aggregated report with no individual's information specified. The study was approved by the Review Board of the Manchester Business School (University of Manchester).

Our informants included people from three different roles namely: Buyers (mainly responsible for buying stocks well in time and at competitive rates), H.R. (responsible for hiring and training new people) and Operations (responsible for processing orders for the internet store). Twenty-two members worked in cubicles and six of them had their own offices. Each individual had a networked computer, phone, calculator and stationery. The open office setting allowed the individuals to communicate amongst each other easily.

Good Store introduced the concept of catalogue shopping in India, and the number of outlets is slowly spreading all around the country with its headquarters in Mumbai. There are a number of products that this retail chain deals with ranging from very basic daily needs to highly sophisticated electronics. There are various departments that look after the restocking of different items. Our informants in the head office served and supplied the request for stocks from people in the outlets, and some of them interacted directly with providers and vendors. Interactions were done by email, but mainly via phone calls. Among the 28 people participating in our study, $18(60 \%)$ were male and $10(40 \%)$ female, most of them were 30 years old or younger $(77 \%)$, and more than half (15) work as buyers and interact with vendors directly. 
The study was conducted using the structured observation technique as described by Mark, et al. [4]. This method has been used by previous similar studies (e.g., [3, 7, $10,14])$. The informants were observed for a period of one hour and twenty minutes on average, with observations evenly distributed across the day. Our goal was to have a larger sample size by limiting the time of observation per individual. The researcher sat right behind the informant and tried to note down and time stamp all the actions performed with as much precision as possible. The notes taken for each action included the time of the day (morning, afternoon, evening), the start time (to the accuracy of seconds), the end time (to the accuracy of seconds), tasks performed, tools used, trigger/task completion (whether internal or external trigger), and the nature of fragmentation (immediate, negotiated, scheduled, unscheduled). Ambiguity regarding the actions performed was resolved at the end of the observation period with the informant. A questionnaire was completed by all the informants, to quantify the various attributes of the information workers in relation to their work environment. The data were analyzed using standard quantitative analysis to produce descriptive statistics and analyze variance.

\section{RESULTS}

We first present an overview of activities and their respective time usage as experienced by our informants (see Table 1). Deskwork is defined as the time individuals work alone with computers and other tools. Our results are similar to those reported by Gonzalez and Mark [3] and Hudson et al. [13]. Our informants spent a large amount of time in unscheduled meetings, face-to-face discussions in their offices and cubicles. An interesting aspect of our study is that our informants spent a large amount of time on the phone. The reason behind this was the type of work they were involved in. Mostly, the buyers had to call up the vendors in order to get the stocks delivered well in time.
We report only significant statistical comparisons. We found that informants, who were allocated personal offices (6), spent more time/hour in unscheduled meetings (mean= $15 \mathrm{~min} 38 \mathrm{sec}$., $\mathrm{sd}=5 \mathrm{~min} 39 \mathrm{sec}$.) as compared to those in cubicles (22) (mean $=9 \min 22$ sec., sd $=6 \min 3$ sec.), $\mathrm{t}(1,26)=0.01, \mathrm{p}<0.03$. Whereas, on the other hand, another $\mathrm{t}-$ test confirms that females (10) spend more uninterrupted time in deskwork events (mean $=5 \mathrm{~min} 27 \mathrm{sec}$., $\mathrm{sd}=3 \mathrm{~min} 46$ sec.) as compared to males (18) (mean $=2 \mathrm{~min} 49 \mathrm{sec}, \mathrm{sd}=1 \mathrm{~min}$ 12 sec.), $\mathrm{t}(1,26)=12.0, \mathrm{p}<0.01$. Females observed then tend to keep focus on activity at hand for a longer period, which can be due to the nature of their activity, as we found an approaching significant difference for non fragmented deskwork time as a result of the role, where non-buyers (most of them females) experience less fragmentation of deskwork time $($ mean $=2 \mathrm{~min} 51$ sec., $\mathrm{sd}=1 \mathrm{~min} 9 \mathrm{sec}$.) as compared to buyers (mean $=4 \mathrm{~min} 49 \mathrm{sec}$., $\mathrm{sd}=3 \mathrm{~min} 33 \mathrm{sec}$.), $\mathrm{t}(1,26)=6.2, \mathrm{p}<0.05$.

Inspired by the switching categories proposed by Bondarenko [7], we coded our data into four main types of switching namely: External Interruptions, Self-Initiated switching, Task Completion and Planned switching. Selfinitiated refers to the switching resulting from the individual himself or herself stopping the task at hand. Task completion on the other hand refers to switching after finishing the task. Planned switching refers to scheduled switching commenced by the individual. For instance, external interruptions often arose as a result of interruptors becoming aware of the activities done by the informant, and they calling their attention to do something related (e.g. call certain vendor requesting a better deal), or for them (e.g. sharing a report). Similarly, and for instance, planning switching was the result of a scheduling activity such as a meeting with their boss or colleagues. In order to identify switching and interruptions, we used identical criteria to those used by Gonzalez and Mark [3] - we recorded task switches that we could readily

Table 1. Time Usage

\begin{tabular}{|c|c|c|c|c|c|}
\hline Activities & $\%$ Time & Average Time/Hour (S.D.) & Average Time/Event (S.D.) & $\begin{array}{c}\text { Gonzalez and Mark (2004) } \\
\%\end{array}$ & $\begin{array}{c}\text { Hudson et al. (2002) } \\
\%\end{array}$ \\
\hline Desk Work & 40.2 & $\begin{array}{c}0: 22: 48 \\
(0: 12: 38)\end{array}$ & $\begin{array}{c}0: 03: 47 \\
(0: 02: 43)\end{array}$ & 36.6 & 42 \\
\hline Phone & 20.1 & $\begin{array}{c}0: 12: 04 \\
(0: 08: 38)\end{array}$ & $\begin{array}{c}0: 01: 58 \\
(0: 01: 00)\end{array}$ & 5.8 & \\
\hline E-mail & 10.2 & $\begin{array}{c}0: 06: 04 \\
(0: 06: 29)\end{array}$ & $\begin{array}{c}0: 02: 02 \\
(0: 01: 02)\end{array}$ & 9.2 & \\
\hline Scheduled Meetings & 3.5 & $\begin{array}{c}0: 01: 58 \\
(0: 03: 40)\end{array}$ & $\begin{array}{c}0: 05: 43 \\
(0: 06: 10)\end{array}$ & 14.4 & 27 \\
\hline Unscheduled Meetings & 17.7 & $\begin{array}{c}0: 11: 06 \\
(0: 06: 59)\end{array}$ & $\begin{array}{c}0: 03: 14 \\
(0: 02: 00)\end{array}$ & 18.9 & 19 \\
\hline Others & 8.3 & $\begin{array}{c}0: 04: 42 \\
(0: 06: 00)\end{array}$ & $\begin{array}{c}0: 04: 33 \\
(0: 10: 18)\end{array}$ & 3 & \\
\hline Total & $100 \%$ & $\begin{array}{c}0: 04: 58 \\
(0: 07: 41)\end{array}$ & $\begin{array}{c}0: 03: 13 \\
(0: 04: 30)\end{array}$ & $100 \%$ & $88 \%^{1}$ \\
\hline
\end{tabular}

For this study $12 \%$ of the time subjects were "to busy to respond". 
Table 2. Work Switching

\begin{tabular}{|c|c|c|c|c|}
\hline Switching & No. of Occurrences & \% of Occurrences & Average Number of Switches/ Hour & \% External $\boldsymbol{v s}$ Internal \\
\hline \hline Interruptions & 288 & 27.5 & 7.91 & 45.3 \\
\hline Self Initiated & 348 & 33.3 & 8.86 & 54.7 \\
\hline Completion & 168 & 15.9 & 4.49 & 7.02 \\
\hline Planned & 245 & 23.3 & 28.28 & $100 \%$ \\
\hline Total & 1049 & $100 \%$ & & \\
\hline
\end{tabular}

identify - e.g. because they involved a switch of technology, or a clear shift of intentional focus.

Gonzalez and Mark [3] report internal interruptions equal to $49.11 \%$ and external interruptions equal to $50.89 \%$ which is similar to the results achieved from this study and those reported in previous managerial research [10].

Table 3. Social Nature vs Functional Aspects

\begin{tabular}{|c|c|c|c|c|}
\hline \multicolumn{3}{|c|}{ Level of Interactivity } & \multicolumn{2}{c|}{ Work Relatedness } \\
\hline $\begin{array}{c}\text { Solitary } \\
\text { Work }\end{array}$ & $\begin{array}{c}\text { Interactive } \\
\text { Work }\end{array}$ & $\begin{array}{c}\text { Other } \\
\text { Work }\end{array}$ & WR & NWR \\
\hline \hline $41.05 \%$ & $51.92 \%$ & $7.03 \%$ & $90.25 \%$ & $9.75 \%$ \\
\hline
\end{tabular}

We then analyzed our data from the perspective of the level of interactivity and work relatedness. Table 3 shows that, either formally $(3.5 \%)$ or informally $(48.42 \%)$, almost $52 \%$ of the time our informants interact with others. Prescheduled and structured meetings were counted as formal; people coming unannounced to the cubicle as informal. This result echoes previous studies (Hudson et al. [13] - 46\%, Perlow [15]-50\%). Our analysis also shows that almost $10 \%$ of the time people's activity is not work related.

We then focused on analyzing the sources of external interruptions as identified in our data - face-to-face, email and phone - with regards their work relatedness. We found that out of the total number of interruptions observed, almost $21 \%$ of them were triggered by non-work related topics (see Table 4). It was observed that apart from face-to-face interruptions, interruptions due to phone calls were also quite high in number. Clearly the main source of interruption is face-to-face but phone is a source of more non-work related interruptions. Our results confirm previous studies reporting face-to-face interactions as a main source of interruptions [3].

Finally, we analyzed the external interruptions to identify the person behind them (interruptor). We identified various interruptors such as peers (P2P), people higher or lower in the organizational hierarchy, external people (EXT) or family members and friends (FMF). Table $\mathbf{5}$ shows that in general, most interruptions came from colleagues, being followed, but with a much lower proportion by those from people outside the company (e.g., vendors). Interestingly, we did not find instances of non work related interruptions from people higher or lower in hierarchy.
Table 4. Work Related $v s$ Non Work Related Interruptions

\begin{tabular}{|c|c|c|c|c|}
\hline \multicolumn{5}{|c|}{$\begin{array}{c}\text { Sources of Interruptions } \\
\text { (Percentage of Occurrence) }\end{array}$} \\
\hline \multirow{2}{*}{ WR } & $\begin{array}{c}\text { F2F } \\
\text { \% }\end{array}$ & $\begin{array}{c}\text { E-Mail } \\
\text { \% }\end{array}$ & $\begin{array}{c}\text { Phone } \\
\%\end{array}$ & $\begin{array}{c}\text { Total } \\
\%\end{array}$ \\
\hline \hline \multirow{3}{*}{ NWR } & 47.91 & 4.34 & 26.92 & 79.17 \\
& $(80.58)$ & $(92.80)$ & $(75.49)$ & \\
\hline \multirow{2}{*}{ Total } & 11.8 & 0.35 & 8.68 & 20.83 \\
& $(19.42)$ & $(7.20)$ & $(24.51)$ & \\
\hline
\end{tabular}

Table 5. Interruptors

\begin{tabular}{|c|c|c|c|c|c|c|}
\hline \multicolumn{7}{|c|}{$\begin{array}{c}\text { Interruptors } \\
\text { (Percentage of Occurrence) }\end{array}$} \\
\hline & $\begin{array}{c}\text { P2P } \\
\%\end{array}$ & $\begin{array}{l}\text { Higher } \\
\%\end{array}$ & $\begin{array}{l}\text { Lower } \\
\%\end{array}$ & $\begin{array}{l}\text { EXT } \\
\%\end{array}$ & $\begin{array}{l}\text { FMF } \\
\%\end{array}$ & $\begin{array}{c}\text { Total } \\
\%\end{array}$ \\
\hline WR & $\begin{array}{c}64.93 \\
(85)\end{array}$ & $\begin{array}{c}4.86 \\
(100)\end{array}$ & $\begin{array}{c}1.39 \\
(100)\end{array}$ & $\begin{array}{c}7.99 \\
(71.92)\end{array}$ & $\begin{array}{c}0 \\
(0)\end{array}$ & 79.17 \\
\hline NWR & $\begin{array}{c}11.46 \\
(15)\end{array}$ & $\begin{array}{c}0 \\
(0)\end{array}$ & $\begin{array}{c}0 \\
(0)\end{array}$ & $\begin{array}{c}3.13 \\
(28.17)\end{array}$ & $\begin{array}{c}6.25 \\
(100)\end{array}$ & 20.83 \\
\hline Total & $\begin{array}{l}76.39 \\
(100)\end{array}$ & $\begin{array}{c}4.86 \\
(100)\end{array}$ & $\begin{array}{c}1.39 \\
(100)\end{array}$ & $\begin{array}{l}11.11 \\
(100)\end{array}$ & $\begin{array}{c}6.25 \\
(100)\end{array}$ & 100 \\
\hline
\end{tabular}

\section{DISCUSSION AND CONCLUSIONS}

The study presented here complements the series of previous studies analyzing the fragmented nature of information work by focusing on a different type of industry and country. Table 1 shows differences between our setting and those in related work, Tables $\mathbf{2}$ and $\mathbf{3}$ shows that, despite these differences, overall statistics about the fragmentation of work remain fairly similar. It is often said, but not always done, that comparative studies should be conducted to consolidate research results. We hope that these results serve to contribute to the consolidation of understanding of work fragmentation. Furthermore, previous studies have shed light on the nature of informal communication highlighting the importance of this for designing technology [6]. We extend those studies beyond face-to-face interactions and look at 
mediated forms of communication such as e-mail and phone when trying to understand work fragmentation and multitasking.

From our results, it is clear that non-work-related activity exists and mixes with work-related activity as a natural characteristic of work. Our methods were tuned to differentiate as much as possible the two types of activity as it is often the case that interaction episodes are mixed with non-work and work related issues. We want to go beyond suggesting that non-work related aspects of work should be supported by new forms of information and communication technologies (ICT), or suggesting that management should be aware of the importance of non-work activity. In fact, what we want is to highlight the phenomenon that either media or managerial approaches often cannot dictate the way people adapt and use the technology. We notice that our study reports non-work-related interruptions when using email in spite that we might considered it as a resource that employees should be using mainly for work-related activities. The increasing popularity and usage of other forms of ICT such as instant messaging or social network tools is likely to exhibit a similar pattern as people find ways to adapt the technology and connect to others either for work or non-work issues. The lesson to be learned is not whether ICT tools should be banned, restricted or designed to certain usage, but to understand that such adaptation and mixed use is often inevitable as it responds to the need of individuals to cover different spheres of work and life.

The main contribution of this paper is our analysis of sources of interruption - in particular our divisions between work-related and non-work-related interruptions. We inspect how this distinction relates to the technology of communication (Table 4) and the characteristics of the interruptor (Table 5). Our results provide a better understanding of social-informal communication in the workplace with regards to how common it is $(10 \%$ of all), how much it fragments work activity $(21 \%$ of all) and who initiates it $(\mathrm{P} 2 \mathrm{P})$. We can then see that social functions served by informal communication take a considerable proportion of workplace activity, being essential for effective collaboration [5].

We cite Kraut et al.'s contention that non-work-related interactions play a functional role in the workplace, but clearly our work cannot be understood as an attempt to directly test this hypothesis. We believe that Kraut's idea predicts that non-work related interruptions will be quite commonplace, and our data support this. The fact that all these interruptions in our sample come from people at the same level of the organization (Table 5) suggests that the management view in this company is contrary to Kraut et al.'s, whatever the truth. This points to the weakness of simply asking participants whether they find the interactions to be of value. Further work and methodological strategies are required to test the phenomenon.

Future work of this study will look at the processes and strategies used to manage the interruptions and will emphasize a micro-level analysis of switching as proposed by other researchers [7].

\section{ACKNOWLEDGEMENTS}

We expressed our gratitude to all participants from Good Store in Mumbai and anonymous reviewers of previous versions of this manuscript. This work has been supported by Asociación Mexicana de Cultura A.C.

\section{REFERENCES}

[1] Golden TD. The role of relationships in understanding telecommuter satisfaction. J Organ Behav 2006; 27(3):319-40.

[2] O'Conaill B, Frohlich D, eds. Timespace in the Workplace: Dealing with Interruptions. Proceedings of (CHI 95) 1995; Denver, Colorado. ACM.

[3] Gonzalez V, Mark G. "Constant, constant, multi-tasking craziness": managing multiple working spheres. Proceedings of the SIGCHI conference on Human factors in computing systems; 2004; Vienna, Austria ACM 2004

[4] Mark G, González V, Harris J, eds. No Task Left Behind? Examining the Nature of Fragmented Work. Proceedings of the SIGCHI conference on Human factors in computing systems (CHI 2005); 2005 April 2-7; Portland, OR. ACM press.

[5] Kraut RE, Fish R, Root R, Chalfonte B. Informal communication in organizations: form, function, and technology. In: Baecker R, editor. Groupware and Computer-Supported Co-operative Work: Morgan Kaufmann 1993; pp. 287-314.

[6] Whittaker S, Frohlich D, Daly-Jones O, eds. Informal workplace communication: What is it like and how might we support it? Proceedings of CHI 94; 1994 April 24-28; Boston, Massachusetts ACM.

[7] Bondarenko O. Task Switching in Detail - Task Identification, Switching Strategies and Influencing Factors. ICEIS Doctoral Consortium 2006; 72-83

[8] Czerwinski M, Horvitz E, Wilhite S. A diary study of task switching and interruptions. Proceedings of the SIGCHI conference on Human factors in computing systems 2004; Vienna, Austria ACM; 2004.

[9] Mintzberg H. Structured observation as a method to study managerial work. J Manage Study 1970; 7: 87-104.

[10] Sproull LS. The Nature of Managerial Attention. Adv Inform Proc Organ 1984; 1: 9-27.

[11] Roy DF. Banana time: Job satisfaction and informal interaction. Human Organ 1960; 18: 156-68.

[12] Handel M, Herbsleb JD. What is chat doing in the workplace? Proceedings of the 2002 ACM conference on Computer supported cooperative work; 2002; New Orleans, Louisiana, USA ACM 2002.

[13] Hudson JM, Christensen J, Kellogg WA, Erickson T, eds. "I'd Be Overwhelmed, But It's Just One More Thing to Do:" Availability and Interruption in Research Management. Proceedings of $\mathrm{CHI}$ 2002; 2002 April 20-25; Minneapolis Minnesota.

[14] Perlow LA. The time famine: toward a sociology of work time. Adm Sci Q 1999; 44: 57-81.

[15] Perlow LA. The time famine: an unintended consequence of the way time is used at work. Boston: Massachusetts Institute of Technology 1995. 